\title{
Effects of long-duration wearing of N95 respirator and surgical facemask: a pilot study
}

\begin{abstract}
The protection efficacy of facemasks and respirators has been well documented. The change of human nasal functions after wearing N95 respirator and surgical facemask is not known. In a parallel group study, we recruited 87 healthy healthcare workers. Each of the volunteers attended two sessions, and wore N95 respirator in session 1 (S1) and surgical facemask in session 2 (S2) for 3hours. Mean minimum cross sectional area (mMCA) of the two nasal airways via acoustic rhinometry and nasal resistance via rhinomanometry were measured before and immediately after the mask wearing. Rhinomanometry was repeated every 30 minutes for 1.5 hours after the removal of masks. A questionnaire was distributed to each of the volunteers, during the 3 hours mask wearing period, to report subjective feelings on discomfort level of breathing activity. Among 77 volunteers who completed both the two sessions, the mean nasal resistance immediately increased upon the removal of surgical facemask and N95 respirator. The mean nasal resistance was significantly higher in S1 than S2 at 0.5 hour and 1.5 hours after removal of the masks $(p<0.01)$. There is no statistical difference on mMCA before and after mask wearing in both sessions ( $\mathrm{p}=0.85$ ). The discomfort level was increasing with time while wearing masks, with significantly higher magnitude in $\mathrm{S} 1(\mathrm{p}<0.001)$. There is an increase of nasal resistance upon removal of N95 respirator and surgical facemask potentially due to nasal physiological changes. N95 respirator caused higher post-wearing nasal resistance than surgical facemask with different recovering routines.
\end{abstract}

Keywords: N95 respirator, surgical facemask, sasal resistance, minimum cross sectional area, discomfort level
Volume I Issue 4 - 2014

\author{
Jian Hua Zhu,' Shu Jin Lee, ${ }^{2}$ De Yun Wang, \\ HeowPueh Lee' \\ 'Department of Mechanical Engineering, Singapore \\ ${ }^{2}$ Department of Surgery, National University Health System, \\ Singapore \\ ${ }^{3}$ Department of Otolaryngology, National University of \\ Singapore, Singapore
}

Correspondence: HeowPueh Lee, Department of Mechanical Engineering, National University of Singapore, Block EA, \#07-08, 9 Engineering Drive I, Singapore I 17575, Tel +65-65 |6-22 I2, Emailmpeleehp@nus.edu.sg

Received: November 12, 2014 | Published: November 22, 2014

\section{Introduction}

Facemasks and respirators are important components of personal protective equipment for health care workers in hospitals and public civilians during severe hazy conditions or influenza pandemic. The efficacy of protection of facemasks and respirators is of importance as they filter fine airborne particles from reaching the respiratory system and prevent inter-individual infection. The protective efficacy of facemasks and respirators has been extensively studied and compared, ${ }^{1}$ by a cluster randomized trial on 794 household members, reported that facemasks seemed to prevent household transmission of influenza virus. Loeb et al., ${ }^{2}$ by a randomized trial on 446 nurses, reported that surgical facemask is not inferior in preventing laboratoryconfirmed influenza compared to N95 respirator, which was criticized to be with various study limitations. ${ }^{3-5}$ On the contrary, another study with cluster randomized clinical trial found that the rate of infection with medical mask was two times of with N95 respirator. ${ }^{6}$ While Atrie et al., ${ }^{7}$ commented that ${ }^{2}$ findings were supportive, the debate on whether the surgical mask is non inferior in preventing influenza than N95 respirator or not is still ongoing. Nevertheless, the difference of protective efficacy between facemask and respirator is conclusive. It was generally accepted that N95 respirator is more effective for filtration compared to facemask. ${ }^{8,9}$

Despite the protective function, the effects of mask wearing on respiratory microclimate, respiratory functions and individual sensations are important as well. It was reported that facemask caused less subjective discomfort feeling, lower perception of humidity, heat and breathe resistance than N95 respirator. ${ }^{10}$ Wearing masks could affect the wearer's whole body thermal sensation. ${ }^{11}$ Long- duration wearing of N95 respirator may induce physiological stress on the wearer, making regular tasks more challenging, and causes headaches among healthcare providers. ${ }^{12}$ These effects might be due to the respiratory microclimate change surrounding the masks. For example, wearing surgical facemask and N95 respirator was found to induce different temperatures and humidification on outer and inner mask surfaces 10 . These differences are attributed to different material properties of the masks, such as lower air permeability and water vapor permeability in N95 respirator. ${ }^{13}$ While the N95 respirator would physically increase the nasal resistance more than $100 \%$ compared to the condition without respirator, ${ }^{14}$ the presence of exhaled moisture or concurrent wearing of surgical facemask has limited effect on breathing resistance..$^{15,16}$

After exposure to masks forhours, the physiological function of nasal cavity may change due to the different humidification and temperature conditions within the mask. However, there is a lack of reported studies on the post effects of wearing N95 respirators or surgical facemasks on human upper airway functions. With this hypothesis, in the current study we aimed to measure the breathing functions in vivo on human subjects using standard rhinomanometry, acoustic rhinometry and spirometry. The findings will be useful for the development and formulation of guidelines and policy for the long duration usage of N95 respirators and surgical facemasks.

\section{Materials and methods}

\section{Study population}

In this parallel group trial, we compared the effects of longduration wearing of surgical facemask and N95 respirator on nasal 
functions. 87 health care workers from the National University Hospital, Singapore were recruited between $13^{\text {th }}$ March 2013 and $21^{\text {st }}$ March 2014, among whom 5 failed to complete all the tests and 2 were not qualified for the criteria of the study. The data of another 3 were not fully collected due to equipment malfunction. In total there are 77 complete data sets collected with 12 male adults and 65 female adults with age ranging between 21 and 60years old.

\section{Study procedures}

Upon the arrival of the volunteers, they would rest at room temperature for 30 minutes. The study consists of initial measurement of nasal geometry using acoustic rhinometry and the inspirational and expirational flow resistance using rhinomanometry included in Rhino-Sys (HappersbergerOtopront $\mathrm{GmbH}$ ). After the initial assessment, each human subject was asked to wear the N95 respirator during the first session and surgical mask during the second session for 3hours. Rhinomanometry and acoustic rhinometry measurements were conducted immediately after the wearing of N95 respirator or surgical facemask followed by repeated measurement at 30minutes interval for a continuous period of 1.5 hours. The study protocols were approved by the institutional review boards of National University of Singapore.

\section{Objective and subjective outcomes}

The mean minimum cross sectional areas (mMCA) of left and right nasal airways were measured at the beginning of each session and right after the removal of respirator/facemask. The inspirational/ expirational nasal resistances were measured at the beginning of each session, and repeated every 30minutes after the removal of respirator/ facemask for 1.5 hours. The nasal resistance was measured at a reference pressure of $150 \mathrm{~Pa}$. The measurements of nasal resistance via rhinomanometry and MCA via acoustic rhinometry were carried out using Rhino-Sys (HappersbergerOtopront $\mathrm{GmbH}$ ). In addition, volunteers were also asked to score subjective feelings on discomfort level of breathing activity every 30 minutes for 3 hours while wearing the respirator/facemask.

\section{Statistical analysis}

We compared the mean inspirational/expirational nasal resistances and subjective discomfort levels at the same time instances between session 1 and session 2 with the use of two-tailed, paired t-tests with significant level of 0.05 . Single-factor ANOVA was used to compare the mMCAs before and after the mask wearing period in sessions 1 and 2 with significant level of 0.05 . A two-sided P value of 0.05 or lower was considered to demonstrate statistical significance.

\section{Results}

Figure 1 shows the mean nasal resistance of the baseline and at the time after removal of masks. The mean nasal resistances of the baseline are slightly different between the two sessions possibly due to nasal cycle. The mean nasal resistance increased immediately after the removal of the respirator, continued to increase in the first hour without mask and decreased in the last half an hour in session 1. In session 2, the mean nasal resistance increased immediately after the removal of the facemask, increased in the first half an hour thereafter, decreased in the second half an hour and then increased to the end. As shown in Table 1, while the baseline nasal resistance and resistances at times of $4 \mathrm{hrs}$ and $5 \mathrm{hrs}$ are similar between the two sessions, the nasal resistance is significantly higher in $\mathrm{S} 1$ than in $\mathrm{S} 2$ at times of $3.5 \mathrm{hrs}$ and $4.5 \mathrm{hrs}(\mathrm{p}<0.01)$. In addition, at one and a half hours after the removal of masks, the mean nasal resistance reached the same level, but larger than the baseline resistance, in both sessions $(\mathrm{p}<0.05)$.

Table 2 shows the mean minimum cross sectional area (mMCA) of left and right nasal airways. In session 1, the mMCA slightly decreased after wearing N95 respirator for 3hours, while in session 2 the mMCA slightly increased. The mMCAs are statistically equal among pre and post conditions of sessions 1 and 2 (ANOVA, $\mathrm{p}=0.85$ ). As shown in Table 3, the mean comfort level is decreasing with time in both sessions 1 and 2, while wearing N95 respirator caused significantly more uncomfortable feelings compared to surgical facemask.

Table I Mean nasal resistance before $(T=0.5 \mathrm{hr})$ and after $(T=3.5,4,4.5$ and $5 \mathrm{hrs})$ mask wearing. ${ }^{*}$ The unit for nasal resistance is $\mathrm{Pa}{ }^{*} / \mathrm{ml}$

\begin{tabular}{|c|c|c|c|c|c|c|c|c|c|c|}
\hline & $\mathrm{T}=0.5$ & & $\mathrm{~T}=3.5$ & & $\mathrm{~T}=4$ & & $\mathrm{~T}=4.5$ & & $\mathbf{T}=5$ & \\
\hline & $\begin{array}{l}\text { Mean } \\
\text { resistance } \\
\pm \mathrm{SD}^{*}\end{array}$ & p-value & $\begin{array}{l}\text { Mean } \\
\text { resistance } \\
\pm S D\end{array}$ & p-value & $\begin{array}{l}\text { Mean } \\
\text { resistance } \\
\pm S D\end{array}$ & p-value & $\begin{array}{l}\text { Mean } \\
\text { resistance } \\
\pm S D\end{array}$ & p-value & $\begin{array}{l}\text { Mean } \\
\text { resistance } \\
\pm S D\end{array}$ & p-value \\
\hline \multirow[t]{2}{*}{$\begin{array}{l}\text { SI } \\
\text { Inspiration }\end{array}$} & $0.44 \pm 0.24$ & & $0.56 \pm 0.34$ & & $0.59 \pm 0.4 \mid$ & & $0.60 \pm 0.46$ & & $0.5 I \pm 0.23$ & \\
\hline & & 0.43 & & $<0.01$ & & 0.33 & & $<0.01$ & & 0.60 \\
\hline $\begin{array}{l}\text { S2 } \\
\text { Inspiration }\end{array}$ & $0.4 I \pm 0.32$ & & $0.45 \pm 0.24$ & & $0.52 \pm 0.53$ & & $0.45 \pm 0.21$ & & $0.50 \pm 0.22$ & \\
\hline \multirow[t]{2}{*}{$\begin{array}{l}\text { SI } \\
\text { Expiration }\end{array}$} & $0.47 \pm 0.28$ & & $0.59 \pm 0.34$ & & $0.63 \pm 0.42$ & & $0.67 \pm 0.60$ & & $0.55 \pm 0.25$ & \\
\hline & & 0.45 & & $<0.01$ & & 0.21 & & $<0.01$ & & 0.59 \\
\hline $\begin{array}{l}\text { S2 } \\
\text { Expiration }\end{array}$ & $0.43 \pm 0.34$ & & $0.49 \pm 0.28$ & & $0.54 \pm 0.47$ & & $0.48 \pm 0.23$ & & $0.53 \pm 0.23$ & \\
\hline
\end{tabular}



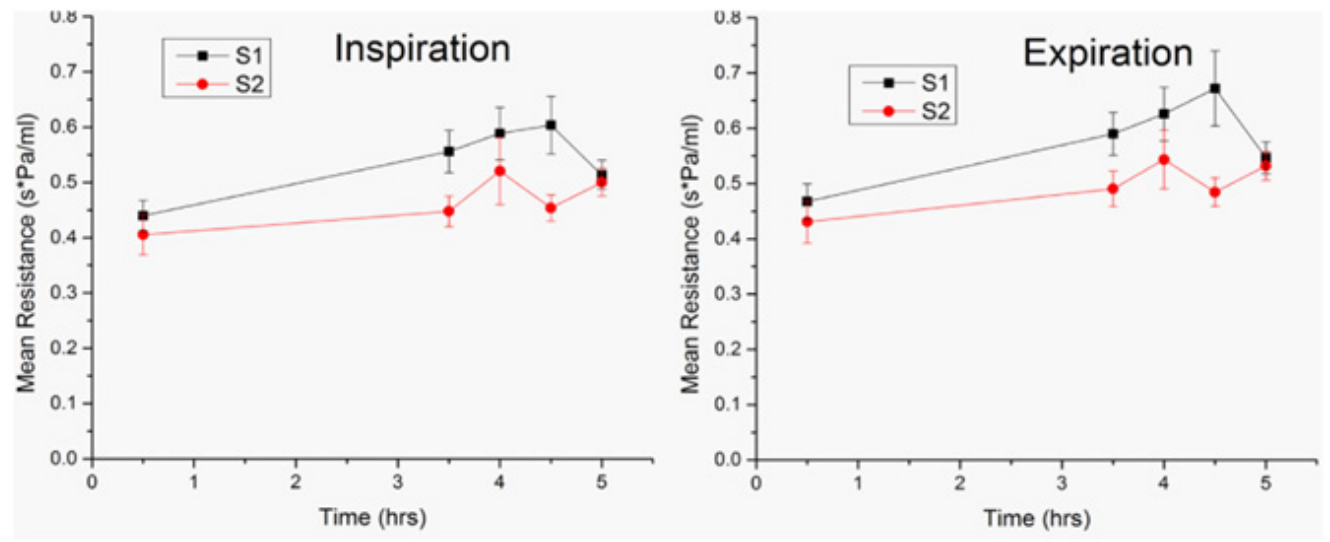

Figure I Mean inspirational/expirational nasal resistance before and after the 3 hours mask wearing period. The I bars represent standard errors.

Table 2 Mean mMCA of the nasal cavity before (Pre) and immediately after (Post) mask wearing

\begin{tabular}{lllll}
\hline & SI & \multicolumn{3}{c}{ S2 } \\
\cline { 2 - 5 } & mMCA $\left(\mathrm{cm}^{2}\right)$ & SD & mMCA $\left(\mathrm{cm}^{2}\right)$ & SD \\
\hline Pre & 0.42 & \pm 0.14 & 0.41 & \pm 0.17 \\
Post & 0.40 & \pm 0.14 & 0.42 & \pm 0.12 \\
\hline
\end{tabular}

Table 3 Mean discomfort level during the 3 hours mask wearing period

\begin{tabular}{|c|c|c|c|}
\hline \multirow{2}{*}{ Time (hr) } & \multicolumn{2}{|c|}{ Mean discomfort levelıSD } & \multirow{2}{*}{ P-value } \\
\hline & SI & S2 & \\
\hline 0.5 & $1.36 \pm 1.40$ & $0.68 \pm 0.94$ & $<0.001$ \\
\hline I & $1.96 \pm 1.62$ & $1.01 \pm 0.99$ & $<0.001$ \\
\hline 1.5 & $2.29 \pm 1.73$ & $1.17 \pm 1.16$ & $<0.001$ \\
\hline 2 & $2.52 \pm 1.79$ & $1.27 \pm 1.26$ & $<0.001$ \\
\hline 2.5 & $2.66 \pm 1.93$ & $1.44 \pm 1.35$ & $<0.001$ \\
\hline 3 & $2.88 \pm 2.03$ & $1.66 \pm 1.62$ & $<0.001$ \\
\hline 3.5 & $3.05 \pm 2.15$ & $1.81 \pm 1.78$ & $<0.001$ \\
\hline
\end{tabular}

\section{Discussion}

As the protection efficacy and possible effects on nasal functions and subjective sensations of wearing N95 respirator/surgical facemask have been well demonstrated, the present pilot study tried to answer the question on whether there is any physiological change of nasal functions upon removal of N95 respirator/surgical facemask after long-duration wearing.

Wearing N95 respirator and surgical facemask would increase the breathing resistance due to the presence of extra layer through the breathing path. An increase of mean resistance during 1.5hours post mask-wearing period was identified in both sessions, indicating potential change of the upper airway conditions. While the mean minimum cross sectional area, as one of the most important parameters to determine nasal resistance, did not significantly differ before and after wearing respirator in session 1 and wearing facemask in session 2 , the increase of nasal resistance after removal of masks is possibly due to physiological change of upper airways. For example, wearing of respirator and facemask altered the fractions of air components and changed microclimate around the nasal cavity, ${ }^{17}$ which would further affects the function of mucosa and its transportation rate. ${ }^{18,19}$

Significantly different mean inspirational/expirational nasal resistances were observed between session 1 with N95 respirator and session 2 with surgical facemask at times of $3.5 \mathrm{hrs}$ and $4.5 \mathrm{hrs}$. This is possibly due to different physical designs and settings. The N95 respirator demonstrates lower air and water vapor permeability. ${ }^{13}$ Subjected to these physical differences, the microclimates in and outside N95 respirator and surgical facemask are also different. The surgical facemask was found to be with higher temperature and humidification on the outer surface, while lower temperature and humidification on the inner surface compared to N95 respirator. ${ }^{10}$ The discomfort level is gradually increasing with time of mask wearing and is lower while wearing surgical facemask than N95 respirator, which is consistent with $\mathrm{Li}$ et al. finding. ${ }^{10}$

\section{Conclusion}

In conclusion, there is an increase of nasal resistance upon removal of N95 respirator and surgical facemask after 3hours wearing which potentially due to nasal physiological changes, instead of the size of nasal airways. The nasal resistance was not recovered even after 1.5 hours removal of respirator/facemask. In addition, the N95 respirator caused higher post-wearing nasal resistance than surgical facemask with different recovery routines. This pilot study has certain limitations. Firstly, the number of volunteers recruited was not large enough to eliminate the magnitude difference of mean nasal resistances at the beginning of sessions 1 and 2, though statistically the null hypothesis is acceptable. Secondly, the time monitored after removal of respirator/facemask, 1.5 hours, was not long enough for the nasal resistance recovering to the baseline level, which is of importance. The limitation in the study time interval is due to the requirement that the volunteers are to remain in the study centre without consumption of foods and therefore we could not keep the volunteers for too long. Thirdly, the effects of nasal cycle could not be ruled out in monitoring the nasal resistance change before and after mask wearing based upon the current test settings.

\section{Acknowledgements}

None.

\section{Conflict of interest}

The author declares no conflict of interest. 


\section{References}

1. Cowling BJ, Chan K-H, Fang VJ, et al. Facemasks and hand hygiene to prevent influenza transmission in households a cluster randomized trial. Annals of Internal Medicine. 2009;151(7):437-446.

2. Loeb M, Dafoe N, Mahony J, et al. Surgical mask vs. n95 respirator for preventing influenza among health care workers:A randomized trial. JAMA. 2009;302(17):1865-1871.

3. Bitar R. Surgical masks vs. n95 respirators for preventing influenza. JAMA. 2010;303(10):937.

4. Clynes N. Surgical masks vs. n95 respirators for preventing influenza. JAMA. 2010;303(10):937-938.

5. Finkelstein Y, Schechter T, Freedman SB. Surgical masks vs. n95 respirators for preventing influenza. JAMA. 2010;303(10):937-939.

6. MacIntyre CR, Wang Q, Cauchemez S, et al. A cluster randomized clinical trial comparing fit-tested and non-fit-tested N95 respirators to medical masks to prevent respiratory virus infection in health care workers. Influenza and Other Respiratory Viruses. 2011;5(3):170-179.

7. Atrie D and Worster A. Surgical mask versus N95 respirator for preventing influenza among health care workers: a randomized trial. Cjem. 2012;14(1):50-52.

8. Bałazy A, Toivola M, Adhikari A, et al. Do N95 respirators provide 95\% protection level against airborne viruses, and how adequate are surgical masks? Am J Infect Control. 2006;34(2):51-57.

9. Oberg T and Brosseau LM. Surgical mask filter and fit performance. Am j Infect Control. 2008;36(4):276-282.

10. Li Y, Tokura H, Guo YP, et al. Effects of wearing N95 and surgical facemasks on heart rate, thermal stress and subjective sensations. Int Arch Occup Environ Health. 2005;78(6):501-509.
11. Farquharson C, Baguley K. Responding to the severe acute respiratory syndrome (SARS) outbreak: Lessons learned in a Toronto emergency department. J Emerg Nurs. 2003;29(3):222-228.

12. Lim ECH, Seet RCS, Lee KH, et al. Headaches and the N95 face-mask amongst healthcare providers. Acta Neurol Scand. 2006;113(3):199-202.

13. Li Y, Wong T, Chung J, et al. In vivo protective performance of N95 respirator and surgical facemask. Am J Ind Med. 206;49(12):1056-1065.

14. Lee HP and Wang DY. Objective assessment of increase in breathing resistance of $\mathrm{N} 95$ respirators on human subjects. Annals of Occupational Hygiene. 2011;55(8):917-21

15. Roberge RJ, Coca A, Williams WJ, et al. Surgical mask placement over N95 filtering face piece respirators: Physiological effects on healthcare workers. Respirology. 2010;15(3):516-521.

16. Roberge RJ, Bayer E, Powell JB, et al. Effect of exhaled moisture on breathing resistance of N95 filtering face piece respirators. Ann Occup Hyg. 2010;54(6):671-677.

17. Laferty EA and McKay RT. Physiologic effects and measurement of carbon dioxide and oxygen levels during qualitative respirator fit testing. Journal of Chemical Health and Safety. 2006;13(5):22-28.

18. Salah B, Dinh Xuan A, Fouilladieu J, et al. Nasal mucociliary transport in healthy subjects is slower when breathing dry air. Eur Respir $J$. 1988;1(9):852-855.

19. Williams R, Rankin N, Smith T, et al. Relationship between the humidity and temperature of inspired gas and the function of the airway mucosa. Crit Care Med. 1996;24(11):1920-1929. 